\title{
Synthesis and biological evaluation of NAS-21 and NAS-91 analogues as potential inhibitors of the mycobacterial FAS-II dehydratase enzyme Rv0636
}

\author{
Correspondence \\ Gurdyal S. Besra \\ g.besra@bham.ac.uk
}

Received 9 February 2008

Revised 18 April 2008

Accepted 21 April 2008

\author{
Veemal Bhowruth, Alistair K. Brown and Gurdyal S. Besra \\ University of Birmingham, School of Biosciences, Edgbaston, Birmingham B15 2TT, UK
}

\begin{abstract}
The identification of potential new anti-tubercular chemotherapeutics is paramount due to the recent emergence of extensively drug-resistant strains of Mycobacterium tuberculosis (XDR-TB). Libraries of NAS-21 and NAS-91 analogues were synthesized and evaluated for their whole-cell activity against Mycobacterium bovis BCG. NAS-21 analogues $\mathbf{1}$ and $\mathbf{2}$ demonstrated enhanced whole-cell activity in comparison to the parental compound, and an M. bovis BCG strain overexpressing the dehydratase enzyme Rv0636 was resistant to these analogues. NAS-91 analogues with ortho-modifications gave enhanced whole-cell activity. However, extension with biphenyl modifications compromised the whole-cell activities of both NAS-21 and NAS-91 analogues. Interestingly, both libraries demonstrated in vitro activity against fatty acid synthase II (FAS-II) but not FAS-I in cell-free extracts. In in vitro assays of FAS-II inhibition, NAS-21 analogues 4 and 5 had $I_{50}$ values of 28 and $19 \mu \mathrm{g} \mathrm{ml}^{-1}$, respectively, for the control M. bovis strain, and the M. bovis BCG strain overexpressing Rv0636 showed a marked increase in resistance. In contrast, NAS-91 analogues demonstrated moderate in vitro activity, although increased resistance was again observed in FAS-II activity assays with the Rv0636overexpressing strain. Fatty acid methyl ester (FAME) and mycolic acid methyl ester (MAME) analysis of $M$. bovis BCG and the Rv0636-overexpressing strain revealed that the effect of the drug was relieved in the overexpressing strain, further implicating and potentially identifying Rv0636 as the target for these known FabZ dehydratase inhibitors. This study has identified candidates for further development as drug therapeutics against the mycobacterial FAS-II dehydratase enzyme.
\end{abstract}

\section{INTRODUCTION}

The emergence of multi-drug resistant Mycobacterium tuberculosis (MDR-TB) (Kaye \& Frieden, 1996) and the more recent identification of extensively drug-resistant $M$. tuberculosis (XDR-TB) (CDC, 2006) has highlighted the need for new TB drugs. Mycolic acids $\left(\mathrm{C}_{60}-\mathrm{C}_{90}\right)$ are vital cell wall components of $M$. tuberculosis which form a lipidrich permeability barrier. Currently, isoniazid represents the mainstay for chemotherapy against TB; it is known to target mycolic acid biosynthesis (Banerjee et al., 1994). Mycolic acid biosynthesis involves both fatty acid synthaseI (FAS-I) and fatty acid synthase-II (FAS-II), with FAS-II being uniquely found in bacteria, plants and apicomplexan parasites, such as Plasmodium (Takayama et al., 2005; Waller et al., 2003). M. tuberculosis FAS-I catalyses de novo synthesis of intermediate-length (principally $\mathrm{C}_{16}$ and $\mathrm{C}_{24}$ )

Abbreviations: ACP, acyl carrier protein; FAMEs/MAMEs, fatty/mycolic acid methyl esters; FAS, fatty acid synthase; $\mathrm{MeOH}$, methanol; MTBE, methyl tert-butyl ether; $\mathrm{NaOMe}$, sodium methoxide; TB, tuberculosis. fatty acids. FAS-II, however, is incapable of de novo fatty acid synthesis and accepts short-chain $\left(\mathrm{C}_{16}\right)$ acyl-CoA primers from FAS-I via a condensation reaction carried out by $\beta$-ketoacyl-ACP synthase III $(m t \mathrm{FabH})$ (Brown et al., 2005; Choi et al., 2000). This newly formed $\beta$-ketoacylACP is reduced by a $\beta$-ketoacyl-ACP reductase (MabA) (Banerjee et al., 1998) to form a $\beta$-hydroxyl-acyl-ACP intermediate. The product is then dehydrated by $\beta$ hydroxyacyl-ACP dehydratase (designated FabA and FabZ in Escherichia coli), followed by further reduction with the enoyl-ACP reductase, InhA, to complete the FASII cycle (Banerjee et al., 1994; Kikuchi \& Kusaka, 1984). Subsequent FAS-II cycles are initiated by the acyl-ACPprimed $\beta$-ketoacyl-ACP synthases KasA and KasB, respectively (Kremer et al., 2000; Mdluli et al., 1998; Schaeffer et al., 2001), to afford a meromycolic acid $\left(C_{56}\right)$, which is then condensed with a $\mathrm{C}_{26}$ fatty acid (Gande et al., 2004; Portevin et al., 2005; Takayama et al., 2005). The oxomycolic acid intermediate is then reduced to form the mature mycolic acid (Lea-Smith et al., 2007). 
The dehydratase enzymes FabZ and FabA have been extensively studied in both E. coli and Plasmodium falciparum (Leesong et al., 1996; Sharma et al., 2003). Both FabZ and FabA catalyse the dehydration of the $\beta$ hydroxylacyl-ACP to a trans-2-enoyl ACP in the third step of fatty acid elongation. In addition to performing the dehydration step, FabA has the ability to isomerize trans-2to cis-3-decanoyl-ACP (Fig. 1), as an essential step in the formation of unsaturated fatty acids in E. coli (Kass \& Bloch, 1967; Kass et al., 1967). The pivotal role played by FabZ and FabA makes them good potential drug targets against $M$. tuberculosis. The identification of the key FAS-II dehydration step in mycobacteria has remained an enigma until very recently (Sacco et al., 2007).

In an attempt to establish whether Rv0636 represented the potential dehydratase candidate, overexpression studies were performed in $M$. bovis BCG against a series of flavonoid inhibitors known to target FabZ (Brown et al., 2007b). Of the five flavonoids tested, four were found to be active against $M$. bovis BCG with MICs ranging from 150 to $220 \mu \mathrm{M}$, the most potent being butein. The activity of the flavonoids against the hypothesized gene product Rv0636 indicated that the overexpression in $M$. bovis BCG conferred resistance to butein and isoliquirtigenin (Brown et al., 2007b). The data suggested that the flavonoids are inhibitors of mycobacterial FAS-II and in particular Rv0636, reiterating the potential candidacy of this gene product as the dehydratase enzyme of the FAS-II in M. tuberculosis.

Sacco et al. (2007) had independently demonstrated that the Rv0635-Rv0637 operon encoded dehydratase activity. The recombinant expression of the candidate protein cluster, Rv0635-Rv0636-Rv0637, led to the formation of two heterodimers, Rv0635-Rv0636 (HadAB) and Rv0636Rv0637 (HadBC), which were shown to also occur in Mycobacterium smegmatis (Sacco et al., 2007). Both heterodimers exhibited the enzymic properties expected for mycobacterial FAS-II dehydratases, including a marked specificity for both long-chain $\left(>\mathrm{C}_{12}\right)$ and ACP-linked substrates (Sacco et al., 2007). Furthermore, the authors of this study were able to show the function of Rv0636 or HadAB/ HadBC as a $\beta$-hydroxyacyl dehydratase when coupled with MabA and InhA enzymes from M. tuberculosis FAS-II.

Further research into potential dehydratase inhibitors has yielded the identification of NAS-21 and NAS-91, which have been shown to target $\beta$-hydroxyacyl-ACP dehydratase FabZ of P. falciparum (Sharma et al., 2003). A decrease in the rate of enzyme activity was observed in the presence of both NAS-21 and NAS-91 using spectrometric and HPLC methods. The authors of that study also showed that the incorporation of $\left[2-{ }^{14} \mathrm{C}\right]$ malonyl-CoA into fatty acids in cell-free extracts of $P$. falciparum was inhibited to different extents by NAS-21 and NAS-91. The incorporation of $\left[1,2-{ }^{14} \mathrm{C}\right]$ acetic acid into fatty acids was reduced by 26 and $46 \%$, respectively, in the presence of $10 \mu \mathrm{M}$ NAS-21 and NAS-91. To investigate the potential anti-mycobacterial therapeutic activity of NAS-21 and NAS-91, we synthesized a library of these FabZ inhibitors. Using a similar strategy to that previously presented (Brown et al., 2007b), we evaluated the analogues for their whole-cell activity against M. bovis BCG and an Rv0636-overexpressing M. bovis BCG strain, and and their in vitro activity against FAS-I and FAS-II in cell-free assays using M. smegmatis extracts.

\section{METHODS}

Synthesis of NAS-21 analogues. A series of NAS-21 analogues were developed using a previously described method (Sharma et al., 2003) (Scheme 1). In brief, acetophenone derivatives were condensed with ethyl trifluoroacetate in the presence of $25 \% \mathrm{NaOMe}$ (in $\mathrm{MeOH})$ and methyl-tert-butyl ether. Diversity was introduced into these reactions using a variety of commercially available acetophenone derivatives, yielding analogues 1-6 (Table 1). Biphenyl analogues 7-9 were developed via Suzuki coupling of 4-iodoacetophenone with aryl boronic acid derivatives. The product was then subjected to treatment with ethyl trifluoroacetate, $25 \% \mathrm{NaOMe}$ in $\mathrm{MeOH}$ and MTBE (Scheme 1) to yield the desired analogues 7-9. An example of the Suzuki coupling reaction for analogue 7 is as follows. 4-Iodoacetophenone (100 mg, $0.292 \mathrm{mmol}, 1 \mathrm{eq}$.), ethylene glycol dimethyl ether $(3 \mathrm{ml})$, aqueous $\mathrm{Na}_{2} \mathrm{CO}_{3}(0.5 \mathrm{ml}, 1 \mathrm{M})$ and 4fluorophenylboronic acid ( $48.97 \mathrm{mg}, 0.37 \mathrm{mmol}, 1.2 \mathrm{eq}$.) in a roundbottom flask was degassed for $10 \mathrm{~min}$. Bis(triphenylphosphine) palladium chloride $\left(8 \mathrm{mg}, 7 \times 10^{-3}, 5 \mathrm{~mol} \%\right)$ was then added and the mixture was heated under reflux for $6 \mathrm{~h}$. The mixture was partitioned between water $(10 \mathrm{ml})$ and ethyl acetate $(10 \mathrm{ml})$ and separated. The aqueous layer was acidified to $\mathrm{pH} 2$ with dilute hydrochloric acid $(2 \mathrm{M})$ and the product was extracted with ethyl acetate $(2 \times 10 \mathrm{ml})$. The organic layers were combined, washed with saturated brine $(3 \times 10 \mathrm{ml})$, dried and reduced to give the crude product. Purification was achieved via two separate silica gel columns. The first column used chloroform in methanol $(95: 5, \mathrm{v} / \mathrm{v})$ as eluant and the second column used ethyl acetate in petroleum ether $(35: 65)$. The title analogue gave a white solid in $78 \%$ yield $(62 \mathrm{mg}) .{ }^{1} \mathrm{H}$ NMR $\left(\mathrm{CDCl}_{3}, 300 \mathrm{MHz}\right) \delta_{\mathrm{H}}: 2.60\left(\mathrm{~s}, 3 \mathrm{H}, \mathrm{CH}_{3}, \mathrm{H}-14\right), 7.05(\mathrm{~d}, 2 \mathrm{H}, \mathrm{H}-5, \mathrm{H}-$ 7, $J=8.5 \mathrm{~Hz}$ ), 7.50 (d, 2H, H-4, H-8, J=8.5 Hz), 7.60 (d, 2H, H-3, H$9, J=8.0 \mathrm{~Hz}), 7.95(\mathrm{~d}, 2 \mathrm{H}, \mathrm{H}-2, \mathrm{H}-10, J=8.0 \mathrm{~Hz}) .{ }^{13} \mathrm{C} \mathrm{NMR}\left(\mathrm{CDCl}_{3}\right.$, $75 \mathrm{MHz}) \delta_{\mathrm{C}}: 23.8$ (C-14), 116.0, 127.4, $129.8(\mathrm{C}-2,3,4,5,7,8,9,10)$, 132.0 (C-12), 136.7 (C-1), 142.0 (C-11), 168.4 (C-6), 195.6 (C-13); $\mathrm{m} / z$ (EI) $214.2\left[\mathrm{M}^{+}\right](100 \%)$; HRMS calculated for $\mathrm{C}_{14} \mathrm{H}_{11} \mathrm{FO}\left[\mathrm{M}^{+}\right]$ 214.2319 found 214.2327 .

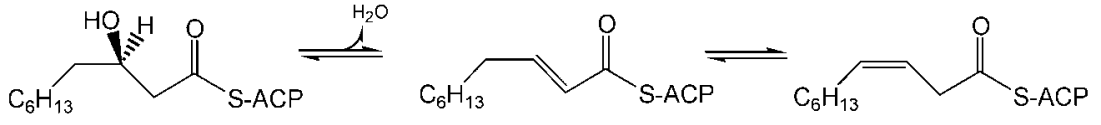

(R)-3-Hydroxydecanoyl-ACP
(E)-2-Decanoyl-ACP
Fig. 1. Dehydration and isomerization of 3hydroxydecanoyl-ACP by E. coli FabA. 

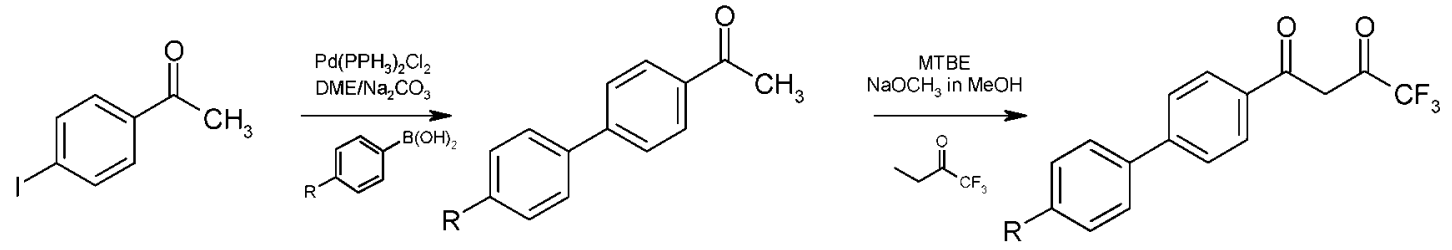

Scheme 1. Method for production of NAS-21 analogues.

Synthesis of NAS-91 analogues. NAS-91 was synthesized as described by Sharma et al. (2003). The reaction involves the coupling of 2-bromo-4-chlorophenol with 5-chloro-8-hydroxyquinolone, using caesium carbonate, copper (I) chloride (0.5 eq.) and $\mathrm{N}$ methylpyrrolidinone as the solvent (Scheme 2) (Ullmann \& Sponagel, 1905). An alternative method was developed to synthesize the remaining NAS-91 analogues in Table 2. A linker arm was introduced into 5-chloro-8-hydroxyquinolone by reacting it with benzyl bromide derivatives under basic conditions (Scheme 3). Diversity was introduced into this library by utilizing a variety of commercially available benzyl bromide derivatives. This method was employed to generate a library of seven novel NAS-91 analogues (10-16) (Table 2), which contain a methylene linker arm connected to the oxygen of 5chloro-8-hydroxyquinolone. As an example, analogue $\mathbf{1 0}$ was synthesized as follows. 5-Chloro-8-hydroxyquinolone (500 mg, $2.78 \mathrm{mmol}, 1$ eq.) was dissolved in $5 \mathrm{ml}$ dimethylformamide. To this was added caesium carbonate $(452 \mathrm{mg}, 1.39 \mathrm{mmol}, 0.5$ eq.). After $20 \mathrm{~min}$ of mixing at room temperature, benzyl bromide $(0.37 \mathrm{ml}$, $3.06 \mathrm{mmol}, 1.1$ eq.) was added dropwise and the reaction was stirred at room temperature overnight. The reaction mixture was quenched with water. The organic layer was extracted with ethyl acetate, washed with water and brine, dried and reduced in vacuo to yield the crude product. The title analogue $\mathbf{1 0}$ was recrystallized to give a white solid in $85 \%$ yield $(635 \mathrm{mg}) .{ }^{1} \mathrm{H}$ NMR $\left(\mathrm{CDCl}_{3}, 300 \mathrm{MHz}\right) \delta_{\mathrm{H}}: 5.35(\mathrm{~s}, 2 \mathrm{H}$, $\left.\mathrm{CH}_{2}, \mathrm{H}-11\right), 6.85$ (d, $\left.1 \mathrm{H}, \mathrm{H}-7, J=8.44 \mathrm{~Hz}\right), 7.15-7.45$ (m, 4H, H-12, H-14, H-15, H-16), 7.48-7.50 (m, 3H, H-3, H-6, H-13), 8.40 (d, 1H, $\mathrm{H}-4, J=8.54 \mathrm{~Hz}), 8.90(\mathrm{~d}, 1 \mathrm{H}, \mathrm{H}-2, J=4.17 \mathrm{~Hz}) .{ }^{13} \mathrm{C} \mathrm{NMR}\left(\mathrm{CDCl}_{3}\right.$, $75 \mathrm{MHz}) \delta_{\mathrm{C}}$ : 68.9 (C-11), 107.8 (C-7), 120.4 (C-3), 124.3 (C-5), 124.5 (C-6), 125.2 (C-13, C-17), 126.1, 126.8, 127.2 (C-15, C-16, C-17), 130.8 (C-4), 134.5 (C-12), 138.1 (C-9), 147.8 (C-2), 153.2 (C-8); $3019.6 \mathrm{~m}, 1638.3 \mathrm{~m}, 1215.6 \mathrm{~s} ; \mathrm{m} / z$ (EI) $369.06\left[\mathrm{M}^{+}\right](30 \%), 91.00$ $\left[\mathrm{C}_{6} \mathrm{H}_{6} \mathrm{CH}_{2}{ }^{+}\right](100 \%)$; HRMS calculated for $\mathrm{C}_{16} \mathrm{H}_{12} \mathrm{ClNO}\left[\mathrm{M}^{+}\right]$ 269.0607 found 269.0603 .

Bacterial strains, growth conditions and $\mathrm{MIC}_{\mathbf{9 g}}$ determination. All reagents were of assay grade and purchased from Sigma-Aldrich. Overexpression of pVV16-Rv0636 (Brown et al., 2007b) was conducted in M. bovis BCG on Middlebrook 7H10 agar supplemented with oleic-albumin-dextrose-catalase (OADC) enrichment (BD and Company) and containing $25 \mu \mathrm{g}$ kanamycin $\mathrm{ml}^{-1}$ and $50 \mu \mathrm{g}$ hygromycin $\mathrm{ml}^{-1}$ (Kremer et al., 1995). Liquid cultures of $M$. bovis BCG were grown at $37{ }^{\circ} \mathrm{C}$ in Sauton's medium containing $25 \mu \mathrm{g}$ kanamycin $\mathrm{ml}^{-1}$ and $50 \mu \mathrm{g}$ hygromycin $\mathrm{ml}^{-1}$. MIC 99 values of NAS analogues against $M$. bovis BCG/pVV16 and $M$. bovis BCG/pVV16Rv0636 were determined by Alamar Blue as described previously using the manufacturer's protocol (Celltiter-Blue; Promega) followed by $\mathrm{MIC}_{99}$ calculations over the concentration range $0-200 \mu \mathrm{g} \mathrm{ml}^{-1}$ (Franzblau et al., 1998).

Determination of the whole-cell effects of NAS analogues on fatty acid and mycolic acid synthesis. M. bovis BCG cultures were grown to $\mathrm{OD}_{600} 0.4$ in the presence of $0.25 \%$ Tween 80 . The NAS analogues were added at various concentrations followed by incubation at $37{ }^{\circ} \mathrm{C}$ for $8 \mathrm{~h}$ and then $1 \mu \mathrm{Ci}(37 \mathrm{kBq}) \mathrm{ml}^{-1}$ $\left[1,2-{ }^{14} \mathrm{C}\right]$ acetate $\left(50-62 \mathrm{mCi} \mathrm{mmol}^{-1}\right.$, GE Healthcare, Amersham Bioscience) was added to the cultures, followed by further incubation at $37{ }^{\circ} \mathrm{C}$ for $16 \mathrm{~h}$. The ${ }^{14} \mathrm{C}$-labelled cells were harvested by centrifugation at $2000 \mathrm{~g}$ followed by washing with PBS. The ${ }^{14} \mathrm{C}$ labelled control and NAS-treated cells were then subjected to alkaline hydrolysis using $5 \%$ aqueous tetrabutylammonium hydroxide at $100{ }^{\circ} \mathrm{C}$ overnight, followed by the addition of $4 \mathrm{ml} \mathrm{CH}_{2} \mathrm{Cl}_{2}, 500 \mu \mathrm{l}$ $\mathrm{CH}_{3} \mathrm{I}$ and $2 \mathrm{ml}$ water, followed by mixing for $30 \mathrm{~min}$. The upper aqueous phase was discarded following centrifugation and the lower organic phase washed three times with water and evaporated to dryness. The resulting fatty acid methyl esters (FAMEs) and mycolic acid methyl esters (MAMEs) were redissolved in diethyl ether, and the supernatant was again removed after centrifugation and evaporated to dryness and redissolved in $200 \mu \mathrm{l} \mathrm{CH}_{2} \mathrm{Cl}_{2}$. An equivalent aliquot $(20 \mu \mathrm{l})$ or equal counts (50000 c.p.m.) of the resulting solution of FAMEs and MAMEs was subjected to TLC using silica gel plates (5735 silica gel $60 \mathrm{~F}_{254}$; Merck), developed in petroleum ether/acetone $(95: 5)$. Autoradiograms were produced by overnight exposure to Kodak X-Omat AR film to reveal ${ }^{14} \mathrm{C}$-labelled FAMEs and MAMEs. Alternatively, free lipids were extracted from the ${ }^{14} \mathrm{C}$-labelled cells and crude lipids examined by TLC for PGL and phospholipid synthesis using the procedures of Dobson et al. (1985).

Preparation of cytosolic fractions, and FAS-I and FAS-II assays. Cytosolic extracts, enriched for FAS-I and FAS-II using ammonium sulphate precipitation, of M. smegmatis $\mathrm{mc}^{2} 155 / \mathrm{pVV} 16$ and $M$. smegmatis $\mathrm{mc}^{2} 155 / \mathrm{pVV} 16-\mathrm{Rv} 0636$ (approx. $10 \mathrm{~g}$ ) were prepared as described previously (Kremer et al., 2002a). The final extract containing the FAS-I and FAS-II activities was dissolved in $5 \mathrm{ml} 50 \mathrm{mM}$ MOPS pH 7.9, $5 \mathrm{mM} \quad \beta$-mercaptoethanol, $10 \mathrm{mM}$ $\mathrm{MgCl}_{2}$. Protein concentrations were determined using the BCA protein assay reagent kit (Pierce). FAS-I and FAS-II assays were conducted as previously described using the $40-80 \%$ ammonium sulfate fraction (Kremer et al., 2002b; Slayden et al., 1996).

\section{RESULTS AND DISCUSSION}

\section{Biological evaluation of NAS-21 analogues}

NAS-2 1 has been shown to target the $\beta$-hydroxylacyl-ACP dehydratase FabZ of P. falciparum (Sharma et al., 2003). The mycobacterial FabZ (Rv0635-637) is a potentially attractive target for such an inhibitor; therefore we sought to synthesize and evaluate NAS-21 analogues against $M$. bovis BCG, which possesses a similar drug profile to $M$. tuberculosis in terms of sensitivity (Larsen et al., 2002; Vilcheze et al., 2005). The results of the whole-cell analysis of NAS-21 analogues against $M$. bovis BCG pVV16 and $M$. bovis BCG/pVV16-Rv0636, which overexpresses Rv0636, are shown in Table 1 . It is clearly evident that the 
Table 1. Structures of NAS-21 analogues, whole-cell inhibitory activity against $M$. bovis BCG and in vitro inhibition of $M$. smegmatis FAS-II activity

\begin{tabular}{|c|c|c|c|c|c|}
\hline \multirow[t]{2}{*}{ Label } & \multirow[t]{2}{*}{ Structure } & \multicolumn{2}{|c|}{$\begin{array}{l}\text { Whole-cell } M \text {. bovis } \\
\text { BCG activity MIC } 99 \\
\quad\left(\mu \mathrm{g} \mathrm{ml}^{-1}\right)\end{array}$} & \multicolumn{2}{|c|}{$\begin{array}{c}\text { In vitro } M \text {. smegmatis } \\
\text { FAS-II activity } \mathrm{IC}_{50} \\
\qquad\left(\mu \mathrm{g} \mathrm{ml}^{-1}\right)\end{array}$} \\
\hline & & pVV16 & $\begin{array}{l}\text { pVV16- } \\
\text { Rv0636 }\end{array}$ & pVV16 & $\begin{array}{l}\text { pVV16- } \\
\text { Rv0636 }\end{array}$ \\
\hline NAS-21 & & 63 & 105 & 94 & 174 \\
\hline 1 & & 49 & 67 & 69 & 92 \\
\hline 2 & & 54 & 77 & 42 & 85 \\
\hline 3 & & 170 & 241 & 35 & 35 \\
\hline 4 & & 78 & 92 & 28 & 72 \\
\hline 5 & & $>250$ & $>250$ & 19 & 74 \\
\hline 6 & & $>250$ & $>250$ & 55 & 84 \\
\hline 7 & & $>250$ & $>250$ & 100 & 152 \\
\hline 8 & & $>250$ & $>250$ & 98 & 165 \\
\hline 9 & & $>250$ & $>250$ & 117 & 125 \\
\hline
\end{tabular}

$\mathrm{COCH}_{2} \mathrm{COCF}_{3}$ group plays a central role in the activity of NAS-21 analogues, because the simple conversion of this group to the $\mathrm{COCH}_{3}$ functionality resulted in the inactivation of the compounds $\left(\mathrm{MIC}_{99}>250 \mu \mathrm{g} \mathrm{ml} \mathrm{m}^{-1}\right.$ ) (data not shown). Two possible explanations for this observed decrease in activity are (i) the di-keto nature of the analogue may mimic the $\beta$-keto substrate utilized in
FAS-II and may act as a competitive inhibitor or (ii) the presence of the $\mathrm{CF}_{3}$ group may stabilize the formation of the keto-enol tautomer of these analogues, which may increase the interaction of the drug with the enzyme's active site. Extension in the para-position of the aromatic ring in NAS-21 resulted in analogues with a significant reduction in activity (Table 1). This is demonstrated by the 
<smiles>Oc1ccc(Cl)cc1Br</smiles>

Scheme 2. Method for production of NAS-91 analogues.

Table 2. Structures of NAS- 91 analogues, whole-cell inhibitory activity against $M$. bovis $B C G$ and in vitro inhibition of $M$. smegmatis FAS-II activity

\begin{tabular}{|c|c|c|c|c|c|}
\hline \multirow[t]{2}{*}{ Label } & \multirow[t]{2}{*}{ Structure } & \multicolumn{2}{|c|}{$\begin{array}{c}\text { Whole-cell M. bovis } \\
\text { BCG activity MIC } 99 \\
\left(\mu \mathrm{g} \mathrm{ml}^{-1}\right)\end{array}$} & \multicolumn{2}{|c|}{$\begin{array}{c}\text { In vitro } M \text {. smegmatis } \\
\text { FAS-II activity } \mathrm{IC}_{50} \\
\left.(\mu \mathrm{g} \mathrm{ml})^{-1}\right)\end{array}$} \\
\hline & & pVV16 & $\begin{array}{l}\text { pVV16- } \\
\text { Rv0636 }\end{array}$ & pVV16 & $\begin{array}{l}\text { pVV16- } \\
\text { Rv0636 }\end{array}$ \\
\hline NAS-91 & & $>250$ & $>250$ & 154 & 185 \\
\hline 10 & & $>250$ & $>250$ & 155 & 165 \\
\hline 11 & & $>250$ & $>250$ & 76 & 176 \\
\hline 12 & & $>250$ & $>250$ & $>200$ & $>200$ \\
\hline 13 & & 43 & $>250$ & 96 & $>200$ \\
\hline 14 & & 50 & 116 & 98 & $>200$ \\
\hline 15 & & 18 & 100 & 98 & 184 \\
\hline 16 & & 78 & 150 & 150 & 185 \\
\hline
\end{tabular}




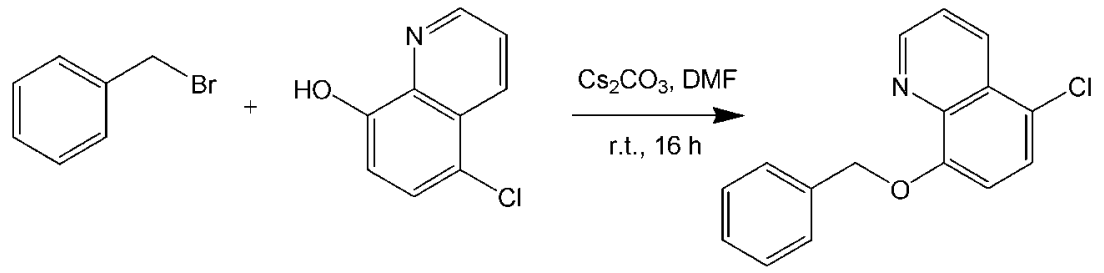

Scheme 3. Method for adding a linker arm to 5-chloro-8-hydroxyquinolone.

biphenyl group (7-9), thus indicating that modifications extending in this position are not well tolerated. Comparable whole-cell activity of the parent drug NAS21 and analogues 1, 2 and 4 was demonstrated against $M$. bovis BCG/pVV16. A significant decrease in whole-cell activity against the Rv0636-overexpressing $M$. bovis BCG strain was also observed, suggesting that the product of this gene may represent the cellular target for NAS-21 and analogues 1, 2 and 4.

\section{Effects of NAS-21 analogues on activity of FAS-I and FAS-II in cell-free extracts}

To further evaluate the biological properties of NAS-21 analogues and to investigate their potential target, Rv0636, a series of in vitro FAS-I and FAS-II assays were performed on crude cell-free extracts of $M$. smegmatis as previously described by Slayden et al. (1996). The analysis was performed on extracts isolated from both M. smegmatis/ pVV16 and M. smegmatis/pVV16-Rv0636. The activity of each analogue was measured by the incorporation of radiolabel into extractable lipids. Specific assays were utilized by using priming units in the form of two different fatty acyl-CoAs, either acetyl-CoA or palmitoyl-CoA, for FAS-I or FAS-II, respectively. In both cases [1, 2$\left.{ }^{14} \mathrm{C}\right]$ malonyl-CoA was utilized as the radiolabelled carbon donor. In the case of FAS-I, $\left[1,2-{ }^{14} \mathrm{C}\right]$ malonyl-CoA coupled with acetyl-CoA to form short-chain fatty acids. However, in the case of FAS-II, $\left[1,2-{ }^{14} \mathrm{C}\right]$ malonyl-CoA is transacylated by $m t \mathrm{FabD}$ to form $\left[1,2-{ }^{14} \mathrm{C}\right]$ malonyl-AcpM, which is subsequently used for the initiation of FAS-II by $m t \mathrm{FabH}$ (Choi et al., 2000). AcpM supplementation in the FAS-II assays drives the reaction towards the production of $\left[1,2-{ }^{14} \mathrm{C}\right]$ malonyl-AcpM. Inhibition $\left(\mathrm{IC}_{50}\right)$ values were determined by varying the concentrations of the drug and by measuring the incorporation of radioactivity into extractable lipids. The results of the crude cell-free extract assay revealed that none of the analogues synthesized inhibited FAS-I (data not shown). Encouragingly, an increased activity was observed for most analogues against FAS-II (Table 1). Analogues $\mathbf{1} \mathbf{- 6}$ gave good in vitro activity against the cell-free $M$. smegmatis pVV16 extracts of FASII. In particular 3, 4 and 5 gave IC $_{50}$ values of 35,28 and $19 \mu \mathrm{g} \mathrm{ml}^{-1}$, respectively, against the M. smegmatis/pVV16 FAS-II extract. An increase in resistance was also observed for $M$. smegmatis/pVV16-Rv0636, further suggesting Rv0636 to be a potential target of the analogues. Interestingly, the whole-cell analysis of analogues $\mathbf{3}$ and $\mathbf{5}$ gave very poor activities (Table 1 ), indicating that these modifications affect the permeability of the drug across the cell wall or that they are modified prior to reaching their target. It was also interesting that analogues $\mathbf{1}$ and $\mathbf{2}$, which gave the most pronounced effects against whole cells of $M$. bovis BCG/pVV16 and M. bovis BCG/pVV16-Rv0636, did not give the same marked response compared to $\mathbf{4}$ and $\mathbf{5}$ in relation to FAS-II inhibition with the same strains (Table 1). Analogues 7-9 were inactive against whole cells; however, moderate activity was observed in FAS-II assays (Table 1), implying that cell permeability may be a contributing factor towards the lack of whole-cell activity of these biphenyl-containing analogues.

\section{Biological evaluation of NAS-91 analogues}

NAS-91 showed poor whole-cell activity against both $M$. bovis BCG/pVV16 and M. bovis BCG/pVV16-Rv0636 and no inhibition was observed even at high concentrations (>250 $\mathrm{g} \mathrm{ml}^{-1}$ ) (Table 2). The observed poor inhibition of $M$. bovis BCG growth was surprising since Gratraud et al. (2008) recently reported an MIC value of $25 \mu \mathrm{g} \mathrm{ml}^{-1}$ against $M$. bovis BCG for NAS-91, although the MIC values reported for NAS-21 $\left(50 \mu \mathrm{g} \mathrm{ml}{ }^{-1}\right)$ by Gratraud et al. (2008) are similar to the values $\left(63 \mu \mathrm{g} \mathrm{ml}^{-1}\right)$ reported in this study. A key feature of note in the studies by Gratraud et al. (2008) was that the MIC values were determined on Middlebrook $7 \mathrm{H} 11$ agar plates by visualizing plaques following serial dilution. In contrast, in this present study, MIC values for NAS-91 (as well as NAS-21) were determined using the more established and sensitive Alamar Blue method (Franzblau et al., 1998) in Sauton's liquid medium. It is clear that MIC values for NAS-91 in particular are different on liquid and solid media. This is not totally surprising since similar observations have been reported for drug inhibition of mycobacterial strains. For instance, $M$. smegmatis is sensitive to econazole and clotrimazole on LB solid agar plates, with MIC values of 2 and $0.5 \mu \mathrm{g} \mathrm{ml}^{-1}$, respectively (Burguiere et al., 2005). However, when M. smegmatis is cultured in Sauton's liquid medium, the MIC values are higher than those determined on agar plates, with econazole at $20 \mu \mathrm{g} \mathrm{m} \mathrm{m}^{-1}$ (10-fold higher) and clotrimazole at $15 \mu \mathrm{g} \mathrm{ml}^{-1}$ (30-fold higher), respectively. Interestingly, it is clear that a concentration of $100 \mu \mathrm{g} \mathrm{ml}^{-1}$ of NAS-91 in liquid media is only partially inhibiting mycolate synthesis (50\%) in the Gratraud et al. (2008) study, which is at four times the MIC value on solid media. This is further evidence for the MIC value for NAS91 being different on solid and liquid media. 
Analogues 13-16 demonstrated significantly improved whole-cell activity in comparison to NAS-91. The simple introduction of a methyl modification in analogue 15 resulted in the most improved whole-cell activity, with an $\mathrm{MIC}_{99}$ value of $18 \mu \mathrm{g} \mathrm{ml}^{-1}$ against $M$. bovis BCG/pVV16. Encouragingly, resistance was shown against analogue 15 when $M$. bovis BCG/pVV16-Rv0636 was used, with an increase in $\mathrm{MIC}_{99}$ to $100 \mu \mathrm{g} \mathrm{ml}^{-1}$. Structurally, analogues 13 and 14 indicate that there is more scope to extend the modification in the ortho-position by two or more carbons. Analogues $\mathbf{1 0}$ and $\mathbf{1 1}$ were primarily developed to assess the feasibility of introducing a linker arm into the analogues whilst changing the functionalities on the aromatic ring. As indicated in Table 2, the low biological activity of these analogues was comparable to that of NAS-91. Initially it was felt that the linker arm might have compromised activity by reorientating the analogue within the active site, thus affecting its interactions with the target. However, as observed with analogues 13-16, modifications in the orthoposition of the aromatic ring greatly increase the potency of this analogue, suggesting it is the nature of the modification on $\mathbf{1 0}$ and $\mathbf{1 1}$ which has compromised their whole-cell activity. From the activities observed with analogues 13-16 it is evident that the hydroxyl group of the secondary aromatic functionality does not play an important part in the protein-drug interaction, as activity was still observed in these analogues. Finally, the introduction of a second aromatic group in the paraposition (12) compromised the whole-cell activity against both $M$. bovis BCG/pVV16 and $M$. bovis BCG/pVV16Rv0636. This initial study suggests that there is limited scope to further extend in the para-position with a second aromatic ring; however, this requires verification by formulating a more comprehensive library.

\section{Effects of NAS-91 analogues on activity of FAS-I and FAS-II in cell-free extracts}

To further evaluate the activities of the NAS-91 analogues, a series of in vitro FAS-I and FAS-II assays were performed on crude cell-free extracts of $M$. smegmatis. As with the NAS-21 analogues, the crude M. smegmatis cell-free FAS-I assays revealed that none of the analogues inhibited FAS-I (data not shown). Analogues $\mathbf{1 0}$ and $\mathbf{1 2}$ demonstrated similar effects to NAS-91 against FAS-II activity in $M$. smegmatis cell-free extracts (Table 2). Encouragingly, analogues 11 and 13-15 gave a marked increase in in vitro activity against FAS-II, and extracts from M. smegmatis/
A

M. bovis BCG/pVV16

M. bovis BCG/pVV16-Rv0636

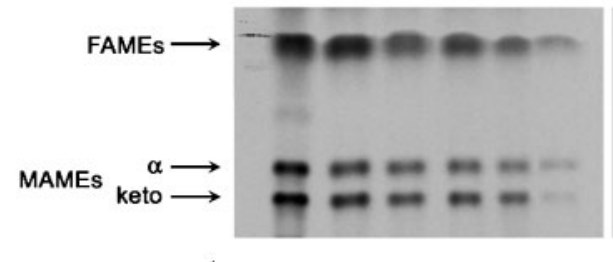

$\left[\mathrm{NAS}-21\left(\mu \mathrm{g} \mathrm{ml}^{-1}\right)\right] \quad \begin{array}{llllll}0 & 10 & 25 & 50 & 75 & 100\end{array}$

M. bovis BCG/pVV16

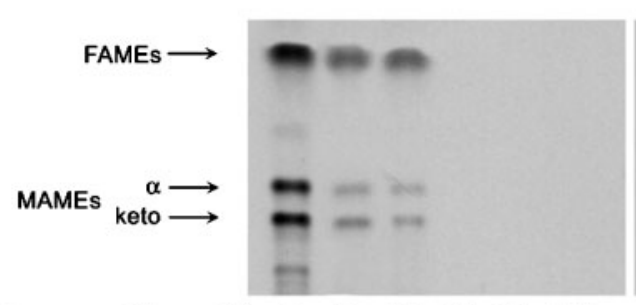

[Compound 1 $\left.\left(\mu \mathrm{g} \mathrm{ml}^{-1}\right)\right] \quad \begin{array}{llllll}0 & 10 & 25 & 50 & 75 & 100\end{array}$

B

\section{M. bovis $\mathrm{BCG} / \mathrm{pVV} 16$}

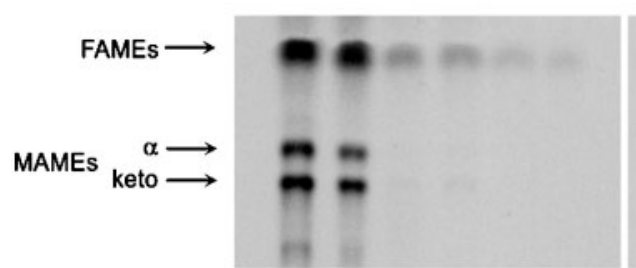

[Compound $\left.15\left(\mu \mathrm{g} \mathrm{ml}^{-1}\right)\right] 0 \quad 10 \quad 25 \quad 50 \quad 75 \quad 100$

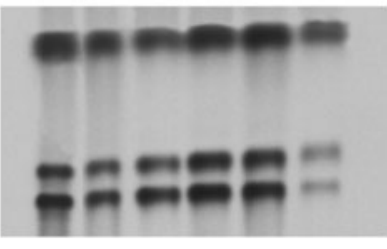

$\begin{array}{llllll}0 & 10 & 25 & 50 & 75 & 100\end{array}$

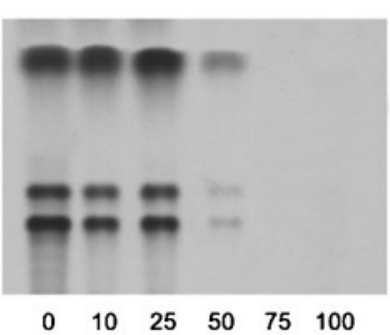

M. bovis BCG/pVV16-Rv0636

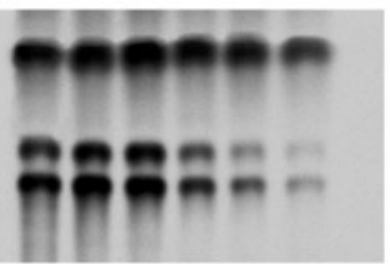

$\begin{array}{llllll}0 & 10 & 25 & 50 & 75 & 100\end{array}$
Fig. 2. TLC-autoradiography of $M$. bovis BCG FAMEs and MAMEs after NAS-21 and NAS91 analogue treatment. (A) NAS-21 analogue $1\left(0-100 \mu \mathrm{g} \mathrm{ml}^{-1}\right)$ and (B) NAS-91 analogue $15\left(0-100 \mu \mathrm{g} \mathrm{m}^{-1}\right)$ were titrated into the $M$. bovis BCG/pVV16 cultures at an $\mathrm{OD}_{600}$ of 0.4 prior to labelling with $1 \mu \mathrm{Ci}(37 \mathrm{kBq})$ $\left[1,2-{ }^{14} \mathrm{C}\right]$ acetate $\mathrm{ml}^{-1}$ for $8 \mathrm{~h} . \quad\left[{ }^{14} \mathrm{C}\right]$ FAMEs and $\left[{ }^{14} \mathrm{C}\right]$ MAMEs were extracted and resolved by TLC. An equivalent aliquot $(20 \mu \mathrm{l})$ of the resulting solution of FAMEs and MAMEs was subjected to TLC using silica gel plates ( 5735 silica gel $60 \mathrm{~F}_{254}$; Merck), developed in petroleum ether/acetone (95:5, v/v). Autoradiograms were produced by overnight exposure to Kodak X-Omat AR film to reveal ${ }^{14} \mathrm{C}$-labelled FAMEs and MAMEs. 
pVV16-Rv0636 FAS-II extract showed resistance to these analogues. Analogues 13-15 also showed good whole-cell activity against whole-cell $M$. bovis BCG/pVV16, providing further evidence that these analogues would form a good basis to generate a secondary library of NAS-91 analogues.

\section{Effects of NAS-21 and NAS-91 analogues on FAME and MAME synthesis}

M. bovis BCG/pVV16 was grown in the presence of the NAS analogues at various concentrations, followed by $\left[1,2-{ }^{14} \mathrm{C}\right]$ acetate labelling and analysis by TLC separation of FAMEs and MAMEs. An example of the results, for analogues 1 and 15, is shown in Fig. 2. There was a decrease in the incorporation of radioactivity into FAMEs and MAMEs in the presence of NAS-21, analogues 1 and $\mathbf{1 5}$. Since analogues $\mathbf{1}$ and $\mathbf{1 5}$ were shown not to inhibit FAS-I (data not shown), the experiment was repeated; equal counts were loaded and the TLC profiles of FAMEs and MAMEs reanalysed (Fig. 3A, D). It is clear from this analysis that analogues $\mathbf{1}$ and $\mathbf{1 5}$ only inhibit the synthesis of $\alpha$ - and keto-MAMEs and not that of FAMEs (Fig. 3), consistent with the earlier in vitro data (Tables 1 and 2). As an additional control the synthesis of cell envelope lipids was also examined (Fig. 3). Analogues 1 and $\mathbf{1 5}$ again do not inhibit general fatty acid synthesis as the synthesis of PGL (Fig. 3B, E) and phospholipids (Fig. 3C, F) remains unaffected. Resistance was also observed upon the overexpression of $\mathrm{pVV16-Rv0636,} \mathrm{supporting} \mathrm{the} \mathrm{earlier} \mathrm{MIC}_{99}$ and in vitro studies and thereby strengthening the evidence that these analogues target Rv0636 (Fig. 2). Similar results were observed with the other active analogues $(2,4,13,14$ and 16).

\section{Concluding remarks}

In conclusion, no activity was observed against FAS-I for either NAS-21 or NAS-91. In general, all the analogues showed in vitro activity against FAS-II extracts, and the Rv0636-overexpressing strain carrying pVV16-Rv0636 showed a marked increase in resistance. Whole-cell FAME and MAME analysis for most analogues demonstrated a decrease in both mycolic acid and fatty acid biosynthesis. Interestingly, this effect of the analogues was also reduced in M. bovis BCG/pVV16-Rv0636, thus further implicating Rv0636 as the target for these FabZ dehydratase inhibitors. The present study extends the initial findings of Gratraud et al. (2008), who did not perform FAS-I and FAS-II in vitro enzyme studies, using NAS-21 and NAS-91 to examine mycolate inhibition directly. Although the study of Gratraud et al. (2008) demonstrated that NAS-21 and NAS-91 also inhibited oleate biosynthesis it is clear that this represents a secondary target since it is nonessential, in contrast to Rv0636, which has been shown to
A

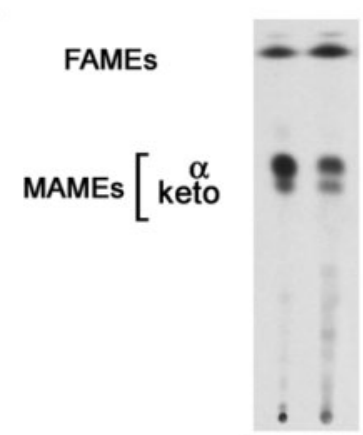

[Comp $\left.1\left(\mu \mathrm{g} \mathrm{ml}^{-1}\right)\right] 020$

D

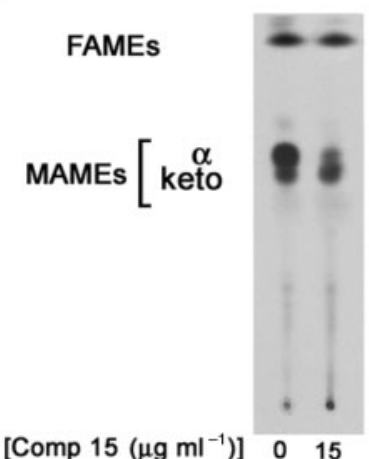

B

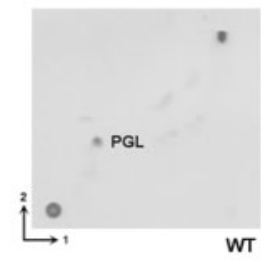

C

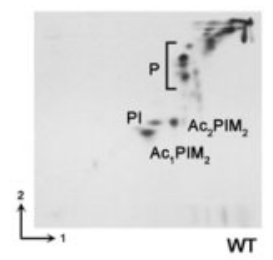

E

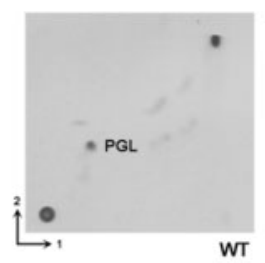

$\mathrm{F}$

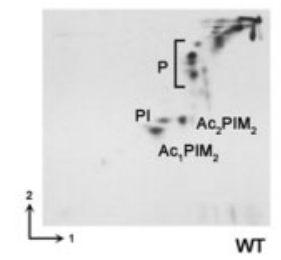

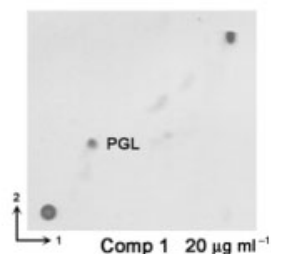
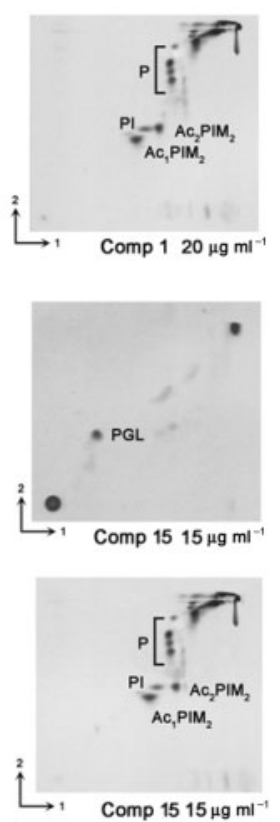

Fig. 3. TLC-autoradiography of $M$. bovis BCG lipids after NAS-21 and NAS-91 analogue treatment. (A, D) Analysis of FAMEs and MAMEs following treatment with NAS-21 analogue $1\left(20 \mu \mathrm{g} \mathrm{ml}^{-1}\right)$ and NAS-91 analogue $15\left(15 \mu \mathrm{g} \mathrm{ml}^{-1}\right)$ and resolved by TLC using equal counts (50000 c.p.m.) as described in Methods. Lipid extractions were performed as described by Dobson et al. (1985) and a 50000 c.p.m. aliquot analysed using silica gel plates (5735 silica gel $60 \mathrm{~F}_{254}$; Merck). (B, E) Phenolic glycolipids (PGL) were identified by 2D TLC [direction 1, chloroform/ methanol $(94: 4, \mathrm{v} / \mathrm{v})$; direction 2, toluene/ acetone $(80: 20, \mathrm{v} / \mathrm{v})]$. (C, F) Phospholipids $(\mathrm{P})$, phosphatidylinositol $(\mathrm{PI})$, acyl-phosphatidylinositol dimannoside $\left(\mathrm{Ac}_{1} \mathrm{PIM}_{2}\right)$ and diacylphosphatidylinositol dimannoside $\left(\mathrm{Ac}_{2} \mathrm{PIM}_{2}\right)$ were identified by 2D TLC [direction 1, chloroform/methanol/water $\quad(60: 30: 6$, by vol.); direction 2, chloroform/acetic acid/ methanol/water $(40: 25: 3: 6$, by vol.)]. Autoradiograms were produced by overnight exposure to Kodak X-Omat AR film to reveal ${ }^{14} \mathrm{C}$-labelled FAMEs, MAMEs and lipids. 
be essential (Brown et al., 2007a). In comparison to the FAS-II flavonoid inhibitors (Brown et al., 2007b), our NAS-21 and NAS-91 analogues demonstrated a marked enhancement in activity; in some cases an eightfold increase is observed. Therefore NAS-21 and NAS-91 analogues represent good candidates for further development of drugs targeting the mycobacterial FAS-II dehydratase. However, to fully establish the potential therapeutic properties of NAS-21 and NAS-91, their in vitro activity against the heterodimers Rv0635-Rv0636 (HadAB) and Rv0636-Rv0637 (HadBC) must be also evaluated. The recent development of an in vitro assay for the FAS-II dehydratase activity (Sacco et al., 2007) will help us to better understand the inhibitory activity of these compounds.

\section{ACKNOWLEDGEMENTS}

G. S. B. acknowledges support in the form of a Royal Society Wolfson Research Merit Award and a Personal Research Chair from Mr James Bardrick, as a former Lister Institute-Jenner Research Fellow, the Medical Research Council (UK), and the Wellcome Trust.

\section{REFERENCES}

Banerjee, A., Dubnau, E., Quemard, A., Balasubramanian, V., Um, K. S., Wilson, T., Collins, D., de Lisle, G. \& Jacobs, W. R., Jr (1994). inh $A$, a gene encoding a target for isoniazid and ethionamide in Mycobacterium tuberculosis. Science 263, 227-230.

Banerjee, A., Sugantino, M., Sacchettini, J. C. \& Jacobs, W. R., Jr (1998). The mabA gene from the inhA operon of Mycobacterium tuberculosis encodes a $\beta$-ketoacyl reductase that fails to confer isoniazid resistance. Microbiology 144, 2697-2704.

Brown, A. K., Sridharan, S., Kremer, L., Lindenberg, S., Dover, L. G., Sacchettini, J. C. \& Besra, G. S. (2005). Probing the mechanism of the Mycobacterium tuberculosis $\beta$-ketoacyl-acyl carrier protein synthase III $m t \mathrm{FabH}$ : factors influencing catalysis and substrate specificity. J Biol Chem 280, 32539-32547.

Brown, A. K., Bhatt, A., Singh, A., Saparia, E., Evans, A. F. \& Besra, G. S. (2007a). Identification of the dehydratase component of the mycobacterial mycolic acid-synthesizing fatty acid synthase-II complex. Microbiology 153, 4166-4173.

Brown, A. K., Papaemmanouil, A., Bhowruth, V., Bhatt, A., Dover, L. G. \& Besra, G. S. (2007b). Flavonoid inhibitors as novel antimycobacterial agents targeting Rv0636, a putative dehydratase enzyme involved in Mycobacterium tuberculosis fatty acid synthase II. Microbiology 153, 3314-3322.

Burguiere, A., Hitchen, P. G., Dover, L. G., Dell, A. \& Besra, G. S. (2005). Altered expression profile of mycobacterial surface glycopeptidolipids following treatment with the antifungal azole inhibitors econazole and clotrimazole. Microbiology 151, 2087-2095.

CDC (2006). Emergence of Mycobacterium tuberculosis with extensive resistance to second-line drugs - worldwide, 2000-2004. MMWR Morb Mortal Wkly Rep 55, 301-305.

Choi, K. H., Kremer, L., Besra, G. S. \& Rock, C. O. (2000). Identification and substrate specificity of $\beta$-ketoacyl (acyl carrier protein) synthase III $(m t \mathrm{FabH})$ from Mycobacterium tuberculosis. J Biol Chem 275, 28201-28207.

Dobson, G., Minnikin, D. E., Minnikin, S. M., Parlett, J. H., Goodfellow, M., Ridell, M. \& Magnusson, M. (1985). Systematic analysis of complex mycobacterial lipids. In Chemical Methods in Bacterial Systematics, pp. 237-265. Edited by M. Goodfellow \& D. E. Minnikin. London: Academic Press.

Franzblau, S. G., Witzig, R. S., McLaughlin, J. C., Torres, P., Madico, G., Hernandez, A., Degnan, M. T., Cook, M. B., Quenzer, V. K. \& other authors (1998). Rapid, low-technology MIC determination with clinical Mycobacterium tuberculosis isolates by using the microplate Alamar Blue assay. J Clin Microbiol 36, 362-366.

Gande, R., Gibson, K. J., Brown, A. K., Krumbach, K., Dover, L. G., Sahm, H., Shioyama, S., Oikawa, T., Besra, G. S. \& Eggeling, L. (2004). Acyl-CoA carboxylases ( $a c c D 2$ and $a c c D 3)$, together with a unique polyketide synthase (Cg-pks), are key to mycolic acid biosynthesis in Corynebacterianeae such as Corynebacterium glutamicum and Mycobacterium tuberculosis. J Biol Chem 279, 44847-44857.

Gratraud, P., Surolia, N., Besra, G., Surolia, A. \& Kremer, L. (2008). Antimycobacterial activity and mechanism of action of NAS-91. Antimicrob Agents Chemother 52, 1162-1166.

Kass, L. R. \& Bloch, K. (1967). On the enzymatic synthesis of unsaturated fatty acids in Escherichia coli. Proc Natl Acad Sci U S A 58, $1168-1173$.

Kass, L. R., Brock, D. J. \& Bloch, K. (1967). $\beta$-hydroxydecanoyl thioester dehydrase. I. Purification and properties. J Biol Chem 242, 4418-4431.

Kaye, K. \& Frieden, T. R. (1996). Tuberculosis control: the relevance of classic principles in an era of acquired immunodeficiency syndrome and multidrug resistance. Epidemiol Rev 18, 52-63.

Kikuchi, S. \& Kusaka, T. (1984). Purification of NADPH-dependent enoyl-CoA reductase involved in the malonyl-CoA dependent fatty acid elongation system of Mycobacterium smegmatis. J Biochem 96, 841-848.

Kremer, L., Baulard, A., Estaquier, J., Content, J., Capron, A. \& Locht, C. (1995). Analysis of the Mycobacterium tuberculosis 85A antigen promoter region. J Bacteriol 177, 642-653.

Kremer, L., Douglas, J. D., Baulard, A. R., Morehouse, C., Guy, M. R., Alland, D., Dover, L. G., Lakey, J. H., Jacobs, W. R., Jr \& other authors (2000). Thiolactomycin and related analogues as novel antimycobacterial agents targeting KasA and KasB condensing enzymes in Mycobacterium tuberculosis. J Biol Chem 275, 16857-16864.

Kremer, L., Dover, L. G., Carrere, S., Nampoothiri, K. M., Lesjean, S., Brown, A. K., Brennan, P. J., Minnikin, D. E., Locht, C. \& Besra, G. S. (2002a). Mycolic acid biosynthesis and enzymic characterization of the $\beta$-ketoacyl-ACP synthase A-condensing enzyme from Mycobacterium tuberculosis. Biochem J 364, 423-430.

Kremer, L., Dover, L. G., Carrere, S., Nampoothiri, K. M., Lesjean, S., Brown, A. K., Brennan, P. J., Minnikin, D. E., Locht, C. \& Besra, G. S. (2002b). Mycolic acid biosynthesis and enzymic characterization of the $\beta$-ketoacyl-ACP synthase A-condensing enzyme from Mycobacterium tuberculosis. Biochem J 364, 423-430.

Larsen, M. H., Vilcheze, C., Kremer, L., Besra, G. S., Parsons, L., Salfinger, M., Heifets, L., Hazbon, M. H., Alland, D. \& other authors (2002). Overexpression of inhA, but not kasA, confers resistance to isoniazid and ethionamide in Mycobacterium smegmatis, M. bovis BCG and M. tuberculosis. Mol Microbiol 46, 453-466.

Lea-Smith, D. J., Pyke, J. S., Tull, D., McConville, M. J., Coppel, R. L. \& Crellin, P. K. (2007). The reductase that catalyzes mycolic motif synthesis is required for efficient attachment of mycolic acids to arabinogalactan. J Biol Chem 282, 11000-11008.

Leesong, M., Henderson, B. S., Gillig, J. R., Schwab, J. M. \& Smith, J. L. (1996). Structure of a dehydratase-isomerase from the bacterial pathway for biosynthesis of unsaturated fatty acids: two catalytic activities in one active site. Structure 4, 253-264. 
Mdluli, K., Slayden, R. A., Zhu, Y., Ramaswamy, S., Pan, X., Mead, D., Crane, D. D., Musser, J. M. \& Barry, C. E., III (1998). Inhibition of a Mycobacterium tuberculosis $\beta$-ketoacyl ACP synthase by isoniazid. Science 280, 1607-1610.

Portevin, D., de Sousa-D’Auria, C., Montrozier, H., Houssin, C., Stella, A., Laneelle, M. A., Bardou, F., Guilhot, C. \& Daffe, M. (2005). The acyl-AMP ligase FadD32 and AccD4-containing acyl-CoA carboxylase are required for the synthesis of mycolic acids and essential for mycobacterial growth: identification of the carboxylation product and determination of the acyl-CoA carboxylase components. J Biol Chem 280, 8862-8874.

Sacco, E., Covarrubias, A. S., O’Hare, H. M., Carroll, P., Eynard, N., Jones, T. A., Parish, T., Daffe, M., Backbro, K. \& Quemard, A. (2007). The missing piece of the type II fatty acid synthase system from Mycobacterium tuberculosis. Proc Natl Acad Sci U S A 104, 14628-14633.

Schaeffer, M. L., Agnihotri, G., Volker, C., Kallender, H., Brennan, P. J. \& Lonsdale, J. T. (2001). Purification and biochemical characterization of the Mycobacterium tuberculosis $\beta$-ketoacyl-acyl carrier protein synthases KasA and KasB. J Biol Chem 276, 47029-47037.

Sharma, S. K., Kapoor, M., Ramya, T. N., Kumar, S., Kumar, G., Modak, R., Sharma, S., Surolia, N. \& Surolia, A. (2003). Identification, characterization, and inhibition of Plasmodium falciparum $\beta$-hydroxyacyl-acyl carrier protein dehydratase (FabZ). $J$ Biol Chem 278, 45661-45671.

Slayden, R. A., Lee, R. E., Armour, J. W., Cooper, A. M., Orme, I. M., Brennan, P. J. \& Besra, G. S. (1996). Antimycobacterial action of thiolactomycin: an inhibitor of fatty acid and mycolic acid synthesis. Antimicrob Agents Chemother 40, 2813-2819.

Takayama, K., Wang, C. \& Besra, G. S. (2005). Pathway to synthesis and processing of mycolic acids in Mycobacterium tuberculosis. Clin Microbiol Rev 18, 81-101.

Ullmann, F. \& Sponagel, P. (1905). Concerning the phenylisation of phenolene. Ber Dtsch Chem Ges 38, 2211-2212.

Vilcheze, C., Weisbrod, T. R., Chen, B., Kremer, L., Hazbon, M. H., Wang, F., Alland, D., Sacchettini, J. C. \& Jacobs, W. R., Jr (2005). Altered $\mathrm{NADH} / \mathrm{NAD}^{+}$ratio mediates coresistance to isoniazid and ethionamide in mycobacteria. Antimicrob Agents Chemother 49, 708-720.

Waller, R. F., Ralph, S. A., Reed, M. B., Su, V., Douglas, J. D., Minnikin, D. E., Cowman, A. F., Besra, G. S. \& McFadden, G. I. (2003). A type II pathway for fatty acid biosynthesis presents drug targets in Plasmodium falciparum. Antimicrob Agents Chemother 47, 297-301.

Edited by: W. Bitter 